\title{
Une forme moderne de la parole traditionnelle : la conférence contée
}

\section{Emmanuelle Saucourt}

\section{(2) OpenEdition}

12 Journals

Édition électronique

URL : http://journals.openedition.org/pa/194

DOI : $10.4000 /$ pa. 194

ISSN : 2273-0362

Éditeur

Université Lumière Lyon 2

\section{Édition imprimée}

Date de publication : 15 janvier 2009

Pagination : 110-116

ISBN : 978-2-912868-62-6

ISSN : 1634-7706

\section{Référence électronique}

Emmanuelle Saucourt, « Une forme moderne de la parole traditionnelle : la conférence contée »,

Parcours anthropologiques [En ligne], 7| 2009, mis en ligne le 02 juillet 2013, consulté le 01 mai 2019.

URL : http://journals.openedition.org/pa/194 ; DOI : 10.4000/pa.194 


\title{
UNE FORME MODERNE DE LA PAROLE TRADITIONNELLE : LA CONFÉRENCE CONTÉE
}

\author{
EMMANUELLE SAUCOURT
}

À partir d'une recherche menée sur le rapport de l'oralité traditionnelle, à travers la figure du conte initiatique peul ${ }^{1}$, à sa mise en écriture, telle que l'a réalisée l'auteur malien Amadou Hampâté Bâ (Saucourt, 2003), c'est toute la question du passage d'une raison (orale) à une autre (graphique), qui interroge le statut du conte : que devient un matériau immatériel comme la parole, jouant un rôle social et culturel pour l'individu et la communauté, lorsqu'il s'ancre dans l'écriture? Peut-on alors considérer le conte mis en écriture comme source fiable de connaissances ethnologiques? Quelle est la part, la nature, du travail littéraire et/ou ethnologique réalisé par l'auteur Hampâté Bâ, pour que ces contes écrits soient des morceaux/fragments d'expression de la culture peul et restent des figures structurantes de l'initiation des bergers?

Parallèlement au terrain africain où ces questionnements sont nés, j'ai développé, depuis une dizaine d'années, avec un ami conteur, une étude expérimentale de contage et de conférence auprès d'un public lyonnais, composé notamment d'immigrés peul de plusieurs pays d'Afrique (Mali, Guinée, Sénégal, Mauritanie). Cette approche d'une culture lointaine par le terrain du proche est née d'une interrogation simple : les contes écrits, comme ceux d'Amadou Hampâté Bâ (1968, 1974, 1976, 1985, 1987), peuvent-ils perpétuer les savoirs d'une culture hors de ses frontières?

En effet, plusieurs observations m'ont conduite à relever que les personnes de culture peul n'allaient pas aisément vers des contes écrits, et que les lecteurs non peul n'accédaient pas facilement à des contes dont les codes culturels leur échappaient. En concertation avec M.D., conteur peul lyonnais, je suis arrivée à la conclusion que les contes d'Hampâté Bâ devaient être de nouveau oralisés pour être écoutés, et que lors de ces moments de contage, la situation d'interlocution revêtait une forme nouvelle.

M.D. est lui-même peul de Guinée, émigré en France depuis une trentaine d'années, d'une famille de la caste des chasseurs, mais également initié à la culture des pasteurs par son oncle maternel auquel il a été confié vers l'âge de onze ans. Ayant eu accès aux contes traditionnels lors de ses initiations et plus simplement au cours de son enfance en

${ }^{1}$ Nous avons pris le parti de conserver à l'adjectif « peul » une forme invariable (NdÉ). 
Guinée, il en a retrouvé un grand nombre dans les ouvrages de l'auteur malien. C'est par cette entremise de l'écriture, alors qu'il était patron d'un restaurant au pied de la Croix-Rousse à Lyon, puis d'un pub, qu'il a commencé à conter, à la demande de ses clients et amis. S'appuyant sur le répertoire traditionnel peul transmis par Hampâté Bâ, à la manière des lettrés peul il a repris les contes, mot à mot, respiration après respiration, en respectant le texte d'origine.

Reprenant vie par la bouche du conteur les contes peul mis en écritures par Hampâté Bâ, devenaient plus accessibles à un public multiculturel. Il restait tout de même d'une part la barrière des codes, que même la situation d'énonciation n'arrivait pas à absorber, et d'autre part l'intérêt croissant des personnes d'origine peul pour leurs traditions souvent oubliées. Le public est alors devenu demandeur d'explication, d'illustration, de développement sur les aspects de certains rites, coutumes et initiations. Le conteur seul, malgré sa capacité à faire des digressions pendant le conte et ses connaissances, ne pouvait pas remplir un tel rôle, celui d'un spécialiste de la culture : un ethnologue. Nous en sommes venus finalement à proposer une forme contemporaine d'incarnation de la parole traditionnelle peul à travers la mise en place de sortes de «conférences contées ». Nous avions dans l'idée de partir d'une conférence et de l'illustrer par des contes choisis, en rapport avec le propos scientifique : réaliser à l'oral l'inverse du travail d'Hampâté Bâ à l'écrit, lui qui a nourri ses contes de notes de bas de page à caractère ethnologique - une sorte d'hypertextualité orale.

\section{Questions Liminaires}

En tant que chercheur, il s'agissait de s'attacher à observer, tout particulièrement, une forme moderne d'actualisation de la parole traditionnelle peul, forme hybride mêlant dans un même moment d'énonciation contes traditionnels, conférence scientifique sur la culture peul et musique. Comment cette association de paroles différentes, traditionnelle, scientifique, musicale, parvient-elle à toucher et relier la communauté, peule et non peule, dans son ensemble? Comment ces conférences-contées deviennent-elles créatrices de réseaux inter-générationnels et inter-culturels? Quelle part de tradition et de modernité cette forme d'énonciation de la parole engage-t-elle? La visée anthropologique de cette recherche tente de mettre à jour les manières dont se construisent, s'inventent des mondes et des imaginaires, ainsi que de détecter les réseaux et les paradigmes culturels qui sous-tendent cette circulation de la parole.

\section{LE DISPOSITIF CLASSIQUE DE CONTAGE}

La distinction entre parole orale et parole écrite se manifeste par une scission entre le sujet et la parole produite : là où la parole orale est 
caractérisée par une impossibilité de séparer le sujet parlant de sa production, l'écriture crée une distance entre le sujet écrivant et sa production. Il s'agit d'insister plus particulièrement ici sur ce qui se joue dans la mise en voix du conte, et par là, sur les liens qui se tissent entre le corps du texte conte et celui du conteur en situation de performance orale, ainsi que sur l'échange qui existe entre le conteur et son auditoire. À propos de la littérature médiévale, qui, sous sa forme orale, a bien des similitudes avec les contes, Paul Zumthor (1987 :248-249) identifie les enjeux d'un moment de contage :

«La transmission de bouche à oreille opère le texte. Mais c'est surtout la performance qui constitue le lieu émotionnel au sein duquel le texte vocalisé devient art, et d'où procède et où tend la totalité des énergies constituant l'œuvre vive. C'est là, en partie, un lieu qualificatif, zone opératoire de la "fonction fantasmatique", selon l'expression de Gilbert Durand. Mais c'est aussi un lieu concret, topographiquement définissable, où la parole en se déployant capte son temps fugace, et en fait un objet de connaissance. Cet objet se confond avec ce qu'elle dit : à quoi fictivement s'identifie l'interprète. "

Ainsi, que se passe-t-il à l'oral qui serait particulier au mode d'expression du conte ? Zumthor propose la notion de "performance » :

«Une personne s'expose dans les mots proférés, dans les vers qu'une voix chante. Je la reçois, j'adhère au discours, à la fois présence et savoir. L'œuvre performée est aussi un dialogue, même si, le plus souvent, un seul des participants $a$ la parole [...] C'est pourquoi le verbe poétique exige la chaleur du contact ; et les dons de sociabilité, l'affectivité rayonnante, le talent de dérider ou d'émouvoir, sinon un certain pittoresque personnel firent partie intégrante d'un art [...] Mais c'est aussi pourquoi l'auditeur-spectateur est en quelque manière coauteur de l'œuvre. »

C'est une situation « exceptionnelle», c'est-à-dire qu'elle n'a lieu qu'une fois, dans un espace et un temps donnés. Elle est exceptionnelle, car même si le conteur est amené à répéter un conte plusieurs fois, elle ne sera jamais exactement reproductible, car le lieu, le temps, le public seront toujours différents. C'est un moment éphémère de la parole, un événement unique où, chaque fois, le texte du conte est en création, en re-création. C'est le propre de la performance du conteur, au sens où le construit Zumthor à partir de la racine de l'ancien français parformer, et dont le sens se rapproche de celui donné par Austin au terme performatif. Quand le conteur se tient devant son auditoire, il fait exister le conte dans le laps de temps de son énonciation. La performance tient à cette rencontre entre le temps, l'espace et des corps en présence, dont naît une création unique et éphémère, non reproductible à l'identique. Quelle que soit la culture, lorsque le conteur prend la parole, il est plus qu'un raconteur d'histoires, il est un intercesseur par lequel s'expriment les interrogations d'une société donnée, les rapports entre les individus, les rapports de l'homme au monde. Il révèle les sensibilités d'un auditoire à l'écoute duquel il est; il sait alors répondre à ses questions, à ses préoccupations et apporter des pistes de réponses et des connaissances nouvelles. Dans l'oralité, le conte est une matière vivante, mouvante que le conteur modèle, à partir d'une ossature intangible, il le déploie en digressions et enluminures selon l'espace, le temps et les corps en présence. 


\section{NAISSANCE D'UN DISPOSITIF : QUAND L'ÉCRIT VIENT NOURRIR L'ORAL}

Que faire lorsque les références du conteur ne sont plus celles du public: rester dans le spectacle " exotique » ou retrouver l'essence du conte : instruire et divertir? Restaurer l'oralité du conte, ou plus spécifiquement transposer à l'oral le travail de guide réalisé à l'écrit par Hampâté Bâ? Dans la plupart des cas, nous n'avons plus de situations, ni de contextes communs au conteur et au lecteur. La distance physique et culturelle qui peut les séparer, ne permet plus les références que Ricœur appelle de " premier rang ", c'est-à-dire celles à un réel immédiat. À l'inverse, le conte à l'écrit développe des références de « deuxième rang ». Ce qui lie alors l'auteur et le lecteur, ce ne sont plus des références du réel commun, mais " une proposition de monde, d'un monde tel que je puisse l'habiter pour y projeter un de mes possibles les plus propres " (Ricœur, 1986 : 127). Là où, à l'oral, le conte est une création dans la performance, à l'écrit, le conte est une création dans la lecture. Il crée son propre visà-vis avec le lecteur à travers la distanciation de l'écriture. Le lecteur s'approprie la proposition de conte que lui fait l'écrivain/conteur.

Ainsi, dans une situation de contage hors contexte culturel peul, comme c'est le cas avec les contes initiatiques que nous proposons lors des conférences contées, nous sommes face au même type de situation que lorsque le conte est à l'écrit : il apparaît alors comme un texte obscur. Il ne peut être immédiatement compris et nécessite le détour d'un long décodage in vitro. Ursula Baumgart (1999:325) explique ainsi ce phénomène :

"L'oralité établit une coöncidence entre le moment de l'énonciation et le moment de la réception, ce qui veut dire qu'il est impossible, comme c'est le cas à l'écrit, d'introduire une distorsion spatio-temporelle entre les deux pôles. Le texte oral ainsi "encadré" par sa performance ne peut donc "voyager" en dehors d'elle pour rencontrer un public potentiellement universel, de la même manière que le texte écrit. Il réunit au contraire une entité culturellement homogène, car celui qui parle et ceux qui écoutent partagent la même langue au moment même où le texte est dit. »

Certes, il est toujours possible de suivre le déroulement narratif du conte, de rentrer dans la fiction et de se laisser étonner par la force du merveilleux, mais les portes essentielles du conte initiatique, celles de l'apprentissage des connaissances exotériques et ésotériques, restent fermées, et par là, celles de toute une culture.

\section{LA LECTURE HyPERTEXUELle, SOURCE DEs CONFÉRENCES CONTÉES}

Le conte oral cependant a ceci de spécifique qu'il existe dans la nonlinéarité de la narration. Non que sa narration soit discontinue et fragmentée - le conte est, de fait, un objet littéraire où la succession narrative est très forte - mais, dans son dispositif d'énonciation, il permet au conteur l'utilisation de la digression. D'où l'importance prise par l'art de 
la glose en situation interculturelle : gloses lexicales et culturelles, destinées à maintenir la relation entre conteur et auditeurs, à instaurer de nouvelles connivences, à l'instar des notes du conte écrit, qui permettent à la pensée du lecteur des chemins arborescents de compréhension.

Or, la lecture des contes écrits semble offrir une possibilité que n'offre pas l'oralité, que traduit la notion de "discontinuité du discours ". Nous l'avons vu, le matériau conte se déroule toujours dans une continuité narrative solide, plus encore lorsqu'il s'agit de contes initiatiques. Ainsi, mis par écrit, ils permettent au lecteur une lecture déconstruite. S'il décide, en effet, de lire les contes en se reportant systématiquement aux notes de bas de page (ou en fin d'ouvrage dans certaines éditions), il entreprend une lecture en discontinu qui les fragmente. Le mouvement de la lecture se fait en forme de montage discontinu - va-et-vient entre la narration, le mot et la note, les notes - constitué de temps morts, transitions d'un texte à l'autre. Le sens du conte naît alors, non pas de sa seule narration écrite, mais de la discontinuité de la lecture qui permet d'entendre le réseau souterrain des échos à distance entre les notes reprises et variées, créant ainsi un espace sémantique parallèle en perpétuelle construction. Là où la lecture seule des notes n'apporterait que des fragments de sens, sans contexte narratif organisant, où la lecture seule des contes serait une vision amputée d'un contexte sémantique culturel riche, l'entrecroisement des deux permet au lecteur une exploration combinatoire de parcours potentiels entre la narration, les explications, les images, les symboles, qui l'invite à revisiter plusieurs fois le texte, pour emprunter des trajets de lecture différents entre les interactions texte/note, note/note, note/œuvres...

Pourquoi donc ne pas réaliser le même va-et-vient à l'oral, quand la plasticité de l'espace et du temps du conte donne de l'aisance au conteur? Cela permet de nouvelles formes d'actualisation de la parole traditionnelle en situation interculturelle où, comme l'ont relevé Nadine Decourt et Naïma Louali (1990:121) :

«La confrontation entre le contage traditionnel et le néocontage permet de mettre en relief l'importance prise par les procédés explicatifs dans le déroulement de la narration. Ils mettent en œuvre un nouveau réseau d'agencement où le conte génère une série de micro-récits. L'imbrication de ces micro-récits à l'intérieur du conte tend à faire de ce dernier le support d'un dialogue interculturel qui participe au plaisir du contage. »

À partir de là, le conte peut à nouveau émerger, prendre des formes nouvelles, devenir inventif in situ.

\section{Présentation du dispositif des Conférences Contées}

Partant de ce principe et ne pouvant retourner à une forme traditionnelle du conte initiatique, nous avons fait des contes des moments digressifs d'une parole académique sur le modèle de distorsion impossible du temps et de l'espace évoqué par Baumgart. Nous n'avons ni cherché à adapter le dispositif traditionnel de contage, qui n'est pas notre mode de 
transmission des connaissances, ni à introduire des procédés explicatifs (symboliques et lexicaux) à l'intérieur des contes, mais nous avons introduit le conte dans la parole savante de la conférence, comme une digression de la conférence.Là où le conte est souvent rangé dans ce que l'on appelle «le spectacle vivant », c'est-à-dire du côté de la culture artistique, nous l'avons associé à la parole scientifique. Non comme objet illustratif, mais comme vecteur différent du même propos. Voici comment se présente une conférence contée. Elle à lieu généralement en soirée, dans l'établissement de M.D. La soirée a été annoncée par voix de presse locale spécialisée dans les spectacles, soit dans la rubrique "conférence", soit à celle « conte » (la différence de catégorisation change couramment le type de public auquel on a à faire) sous le titre de " conférence contée autour de la culture peul avec le conteur M.D. et l'ethnologue E.S. », suivi du tarif d'entrée. La veillée se structure de la façon suivante :

- ouverture de la séance par des paroles inaugurales et ritualisées des musiciens qui appellent le conteur,

- le conteur souhaite la bienvenue au public et appelle l'ethnologue,

- conférence et contes intercalés,

- clôture de la conférence, systématiquement par le même conte et remerciement des participants,

- collation offerte par le conteur au public et moment d'échange convivial.

Ce dispositif proposé au public, et répété sur trois années, s'est naturellement modifié à l'usage. Il a évolué au rythme des voix qui se répondent. Rencontre de deux modes d'expression, de deux vecteurs de connaissances : l'un a parfois absorbé l'autre, l'un et l'autre se sont parfois juste côtoyés, mais souvent ils se sont imbriqués et ont dialogué.

Conférence et conte se sont entremêlés, l'une devenant l'écho de l'autre - deux paroles et deux voix : le conférencier et le conteur. Petit à petit, la parole savante s'est mise à conter et le conteur à exposer et expliquer des rites initiatiques, des coutumes, des chants.

En relisant les notes préparatoires des séances sur plusieurs années, en s'attachant à la même conférence contée sur les initiations peul reproduite plusieurs fois, on peut identifier ces glissements. Conjointement à ces observations s'est développé un indicateur étonnant de ce glissement, de ce tissage des paroles : les musiciens (percussion, guitare) n'étaient plus accompagnateurs, mais soutenaient la parole, quelle qu'elle soit, faisant lien entre la conférence et le conte. Comme un liant, plus encore, une troisième voix en dialogue.

Nous en retrouvons souvent des traces de ces glissements dans les travaux préparatoires effectués avec le conteur et les musiciens. Ainsi, il est remarquable de constater que toujours l'écrit savant a fait surgir l'oral du conteur qui lui-même venait nourrir la parole de l'ethnologue : je lisais ma conférence rédigée au conteur; au cours de cette lecture, il laissait surgir des contes, des récits généalogiques, des anecdotes; je les recueillais pour les réintroduire dans le corps de la conférence, puis je remodelais mes notes pour l'oral et le conteur relisait ses contes écrits. Imbrication des genres, des voix, des raisons orale et graphique. À ce moment-là de notre élaboration, les musiciens lisaient la trame de la 
conférence contée, se l'appropriaient en laissant eux aussi ressurgir des traces de leur propre culture. La musique ainsi inspirée de la thématique de la soirée, allait puiser dans les souvenirs du pays, dans d'autres contes oubliés, pour donner un corps aux mots au moment de l'énonciation. La musique venant nourrir les paroles par le sensible, le tangible. Étrange sensation pour un ethnologue que de participer à un tel entremêlement de cultures, de registre de paroles et d'imaginaires.

Cette expérience a fait naître de nombreuses questions directement liées à l'actualisation d'une parole traditionnelle en situation d'expatriation : cette association de paroles différentes, traditionnelles, scientifiques, musicales, parvient-elles à toucher et relier les communautés, peul et non peul? Dans quelles mesures ces conférences contées deviennent-elles créatrices de réseaux inter-générationnels et inter-culturels? Jusqu'à quel point cette forme de parole peut-elle redonner au conte son rôle de vecteur de connaissances et de savoirs?

\section{Bibliographie}

BAUMGARDT U., «Littérature orale et identité », in Botte R., Boutrais J. \& Schmitz J. (dir.), Figures peules, Paris, Karthala, 1999.

Decourt N. \& Louali N., "Les procédés du contage. Du conte traditionnel au néocontage », Littérature Orale Arabo-Berbère 21, 1990.

HampÂté BÂ \& G. Dieterlen, Koumen, texte initiatique des pasteurs peul, éd. Mouton, 1961.

— \& L.Kesteloot, Kaïdara, récit initiatique peul, Paris, Julliard, 1968.

- A. Ibrahim Sow \& C. Seydou, L'Éclat de la Grande Étoile, conte initiatique peul, Paris, A. Colin, 1974.

- A. Ibrahim Sow \& C. Seydou, Bain rituel, conte initiatique peul, coll. Classiques Africains, Paris, 1974.

- Petit Bodiel, conte drôlatique peul, Abidjan, N.E.A., 1976.

- Njeddo Dewal, mère de la calamité, conte initiatique peul, Abidjan, N.E.A., 1985. 1987.

- La poignée de poussière, contes et récits du Mali, Abidjan, N.E.A.,

Riceur P., Du texte à l'action, Paris, Seuil, 1986.

SAucourt E., "Oralité ou écriture du conte : questions autour de l'auteur Amadou Hampâté Bâ», Histoire et Anthropologie, n 2, juin 2003.

— «De l'oralité à l'écriture : Amadou Hampâté Bâ » in J.-B. Martin et N. Decourt (éds.), Littérature orale : paroles vivantes et mouvantes, Lyon, PUL, 2003.

Zumthor P., La lettre et la voix, Paris, Seuil, 1987. 